\title{
IMPLEMENTASI MODEL PEMBELAJARAN KOOPERATIF TIPE EXAMPLE NON EXAMPLE UNTUK MENINGKATKAN PEMAHAMAN DAN KETERAMPILAN KOOPERATIF SISWA KELAS VII SMP PADA MATERI HIMPUNAN
}

\author{
Ariesta Kartika Sari ${ }^{1}$, Muchamad Arif ${ }^{2}$, Sudarsono ${ }^{3}$, Holifah ${ }^{4}$ \\ ,2 Program Studi Pendidikan Informatika, FIP Universitas Trunojoyo Madura \\ ${ }^{3,4}$ SMPN 2 Socah Bangkalan Madura
}

\begin{abstract}
This study aims to (1) improve the understanding of $7^{\text {th }}$ grade students on set material, (2) describe the cooperative skills of students after following the cooperative learning model type Example Non Example. This research is a collaborative classroom action research. Participants in this classroom action research are 16 class $7^{\text {th }}$ SMPN 2 Socah Bangkalan Madura. The stages of classroom action research in this study refer to Bachman's Spiral model (in Mertler, 2014: 19). The stages in this classroom action research consist of: Plan, Action, Observation, and Reflection. The learning model applied in this study is the cooperative learning model type Example Non Example. The focus of the material in this study is the set material of Mathematics subjects. The implementation of this classroom action research consists of two cycles. The application of cooperative learning model type Example Non Example gives results that: (1) the average student understanding in the first cycle reaches $68.8 \%$. While the understanding of students in the second cycle reached $82.5 \%$. Students' cooperative skills in this study consist of skills: (a) appreciating contributions, (b) being in groups, (c) listening, and $(d)$ asking. After following the implementation of the Example Non Example cooperative learning model, the cooperative skills of students in the first cycle reached $73 \%$ (good). Whereas in the second cycle, students' cooperative skills reached $91 \%$ (very good)..
\end{abstract}

Keyword: Cooperative Learning, Example Non Example, Set

\begin{abstract}
ABSTRAK
Penelitian ini bertujuan untuk (1) meningkatkan pemahaman siswa kelas VII terhadap materi himpunan, (2) mendeskripsikan keterampilan kooperatif siswa setelah mengikuti model pembelajaran kooperatif tipe Example Non Example. Penelitian ini merupakan penelitian tindakan kelas yang kolaboratif. Participan penelitian tindakan kelas ini adalah 16 kelas VII SMPN 2 Socah Bangkalan Madura. Tahapan-tahapan dalam penelitian tindakan kelas pada penelitian ini mengacu pada model Spiral-nya Bachman (dalam Mertler, 2014:19). Adapun tahapan dalam penelitian tindakan kelas ini terdiri atas: Rencana, Tindakan, Observasi, dan Refleksi. Model Pembelajaran yang diterapkan dalam penelitian ini adalah model pembelajaran kooperatif tipe Example Non Example. Fokus materi pada penelitian ini adalah materi himpunan pada matapelajaran Matematika. Pelaksanaan Penelitian tindakan kelas ini terdiri atas dua siklus. Penerapan model pembelajaran kooperatif tipe Example Non Example memberikan hasil bahwa : (1) rata-rata pemahaman siswa pada siklus pertama mencapai $68,8 \%$. Sedangkan pemahaman siswa pada siklus kedua mencapai sebesar $82,5 \%$. Keterampilan kooperatif siswa dalam penelitian ini terdiri atas keterampilan : (a) menghargai kontribusi, (b) berada dalam kelompok, (c) mendengarkan, dan (d) bertanya. Setelah mengikuti pelaksanaan model pembelajaran kooperatif tipe Example Non Example, keterampilan kooperatif siswa pada siklus pertama mencapai $73 \%$ (baik). Sedangkan pada siklus kedua, keterampilan kooperatif siswa mencapai 91\% (sangat baik).
\end{abstract}

Kata Kunci: Pembelajaran Kooperatif, Example Non Example, Himpunan

\footnotetext{
${ }^{1)}$ Korespondensi : Ariesta Kartika Sari. Program Studi Pendidikan Informatika, FIP Universitas Trunojoyo Madura Email: ariestakartika@ymail.com

${ }^{2)}$ Korespondensi : Muchamad Arif. Program Studi Pendidikan Informatika, FIP Universitas Trunojoyo Madura Email: muchamadarif83@gmail.com

${ }^{3)}$ Korespondensi : Sudarsono. SMPN 2 Socah Bangkalan Madura

${ }^{4)}$ Korespondensi : Holifah. SMPN 2 Socah Bangkalan Madura
} 


\section{PENDAHULUAN}

Mata pelajaran Matematika merupakan salah satu mata pelajaran yang diharapkan dapat meningkatkan logika berfikir siswa. Namun, kerap kali mata pelajaran Matematika dianggap sebagai suatu subjek materi yang sulit bagi siswa. demikian hal yang sama terjadi, ketika peneliti melakukan tahap pra-penelitian, dengan cara observasi dan wawancara terhadap siswa kelas VII SMPN 2 Socah Bangkalan, yang menghasilkan bahwa hampir 90\% siswa berpendapat bahwa Matematika merupakan mata pelajaran yang sulit.

Mindset terkait Matematika merupakan mata pelajaran yang sulit bagi siswa, dapat dimungkinkan diperoleh dari pengalaman belajar siswa pada masa sebelumnya dalam pembelajaran matematika. Wawancara peneliti terhadap narasumber guru Matematika di SMPN 2 Socah Bangkalan menghasilkan bahwa siswa-siswi ang notabene berada dalam kelas VII masih harus selalu diinstruksi untuk fokus dalam belajar. Narasumber juga mengungkapkan sebagian pemahaman siswa masih kurang dalam mata pelajaran Matematika. Aktivitas belajar di dalam kelas pun mayoritas masih didominasi oleh guru. Hal ini tampak saat pembelajaran berlangsung, siswa banyak diam saat guru bertanya tentang kesulitan apa yang dialami saat mempelajari materi. Aktivitas siswa dalam bertanya/ berdiskusi juga masih kurang, hal ini tampak saat guru meminta siswa untuk bertanya ataupun berpendapat dalam diskusi, namun ternyata mayoritas siswa tidak memanfaatkan kesempatan tersebut.

Berdasarkan pada pengalaman guru (narasumber) dalam tahapan wawancara dan observasi tersebut (pra-penelitian), maka penelitian tindakan kelas ini memiliki tujuan : (1) meningkatkan pemahaman siswa kelas VII SMP terhadap matapelajaran Matematika materi himpunan, mendeskripsikan respon siswa setelah mengikuti pembelajaran dengan model kooperatif tipe Example Non Example..

Menurut Rusman (2012: 203) model pembelajaran kooperatif adalah strategi pembelajaran yang melibatkan partisipasi siswa dalam satu kelompok kecil untuk saling berinteraksi. Dengan diterapkannya model pembelajaran kooperatif dalam suatu pembelajaran dapat membuat siswa lebih aktif karena model pembelajaran kooperatif ini merupakan bentuk pembelajaran dengan cara siswa belajar dan bekerjasama dalam kelompok-kelompok kecil yang dapat membuat siswa saling berinteraksi. Salah satu model pembelajaran kooperatif yang 
cocok untuk digunakan dalam kegiatan belajar mengajar mata pelajaran Matematika, khususnya materi himpunan adalah model pembelajaran kooperatif tipe Example Non Example.

Ibrahim, dkk (2000: 7-9) menerangkan bahwa tujuan model pembelajaran kooperatif dikembangkan untuk mencapai setidak-tidaknya tiga tujuan pembelajaran sebagai berikut, yaitu

1. Hasil belajar akademik

2. Penerimaan terhadap keragaman/ perbedaan individu

3. Pengembangan keterampilan social. dengan demikian, penerapan model pembelajaran kooperatif dalam mata pelajaran Matematika materi himpunan, diharapkan dapat meningkatkan pemahaman siswa (yang diiwujudkan melalui hasil belajar kongnitif) serta dapat meningkatkan keterampilan berdiskusi/ bertanya/ mengemukakan pendapat dalam kegiatan pembelajaran.

Langkah-langkah dalam model pembelajaran kooperatif pada penelitian ini mengacu pada enam langkah utama di dalam pelajaran yang menggunakan model pembelajaran kooperatif dalam bukunya Ibrahim, dkk (2000: 10). Keenam fase utama tersebut antara lain :
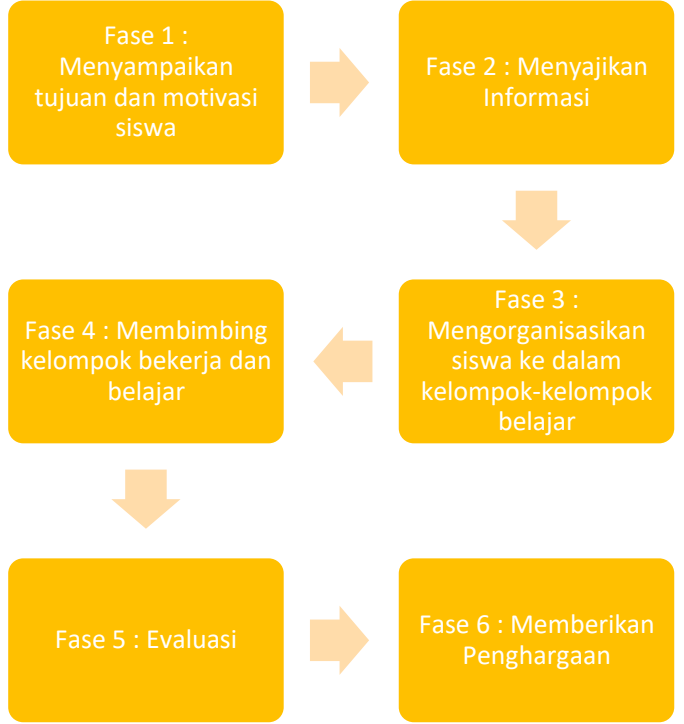

Gambar 1 : Enam langkah utama Model Pembelajaran Kooperatif

Menurut Kurniasih (2017: 31) Tipe Example non example merupakan pembelajaran yang menggunakan gambar sebagai media untuk menyampaikan materi pelajaran, dengan tujuan untuk mendorong siswa agar belajar berfikir kritis dengan jalan memecahkan permasalahan-permasalahan yang termuat dalam contoh-contoh gambar dipersiapkan terlebih dahulu oleh guru. Langkah-langkah model pembelajaran kooperatif tipe Example non example pada penelitian ini mengadaptasi dari enam langkah utama dari Ibrahim, dkk (2000: 10) dan Suprijono (dalam Shoimin, 2014: 74). Adapun langkah-langkah model pembelajaran kooperatif tipe Example Non Example pada penelitian ini disajikan pada Tabel berikut ini: 


\section{Tabel 1. Langkah Model Pembelajaran} Kooperatif Tipe Example Non Example

\begin{tabular}{|c|c|}
\hline FASE & TINGKAH LAKI \\
\hline $\begin{array}{l}\text { Fase-1 } \\
\text { Menyampai- } \\
\text { kan tujuan } \\
\text { dan } \\
\text { memotivasi } \\
\text { siswa }\end{array}$ & $\begin{array}{l}\text { Guru menyampaikan tujuan } \\
\text { pembelajaran dan memotivasi } \\
\text { siswa mengenai pentingnya } \\
\text { mempelajari materi himpunan } \\
\text { dalam kehidupan sehari-hari. }\end{array}$ \\
\hline $\begin{array}{l}\text { Fase-2 } \\
\text { Menyajikan } \\
\text { informasi } \\
\text { berupa } \\
\text { materi } \\
\text { gambar } \\
\text { example non } \\
\text { example }\end{array}$ & $\begin{aligned} & \text { Guru menjelaskan tahapan } \\
& \text { pembelajaran yang akan } \text { dilaksanakan } \\
&> \text { Guru mempersiapkan } \\
& \text { gambar-gambar yang sesuai } \\
& \text { dengan tujuan } \\
& \text { pembelajaran. } \\
& \text { Guru menempelkan gambar } \\
& \text { di papan atau ditayangkan } \\
& \text { melalui LCD. } \\
& \text { Guru memberi informasi, } \\
& \text { petunjuk dan kesempatan } \\
& \text { kepada siswa untuk } \\
& \text { menganalisis gambar } \\
& \text { (example non example) dan } \\
& \text { mengemukakan } \\
& \text { pendapatnya. }\end{aligned}$ \\
\hline $\begin{array}{l}\text { Mengorganis } \\
\text { asikan siswa } \\
\text { dalam bentuk } \\
\text { kelompok } \\
\text { diskusi } \\
\text { belajar }\end{array}$ & \begin{tabular}{rlr} 
& Guru mengelompokkan \\
& siswa dalam kelompok kecil \\
& \multicolumn{2}{l}{ yang terdiri atas $4-5$ siswa } \\
$>$ & Guru memberi & tugas \\
& kelompok & untuk \\
& didiskusikan bersama dalam \\
kelompok (berupa analisis \\
gambar example non \\
example) \\
Guru mengarahkan siswa \\
untuk mempelajari dan \\
mendiskusikan \\
permasalahan dalam lembar \\
kerja kelompok.
\end{tabular} \\
\hline $\begin{array}{l}\text { Membimbin } \\
\mathrm{g} \quad \text { siswa } \\
\text { dalam belajar } \\
\text { kelompok }\end{array}$ & $\begin{array}{l}\text { Guru mendorong siswa } \\
\text { untuk melakukan diskusi } \\
\text { kelompok kecil dan } \\
\text { mengumpulkan informasi } \\
\text { terkait penyelesaian tugas }\end{array}$ \\
\hline
\end{tabular}

\begin{tabular}{|c|c|}
\hline $\begin{array}{l}\text { dan } \\
\text { menyajikan } \\
\text { hasil diskusi }\end{array}$ & 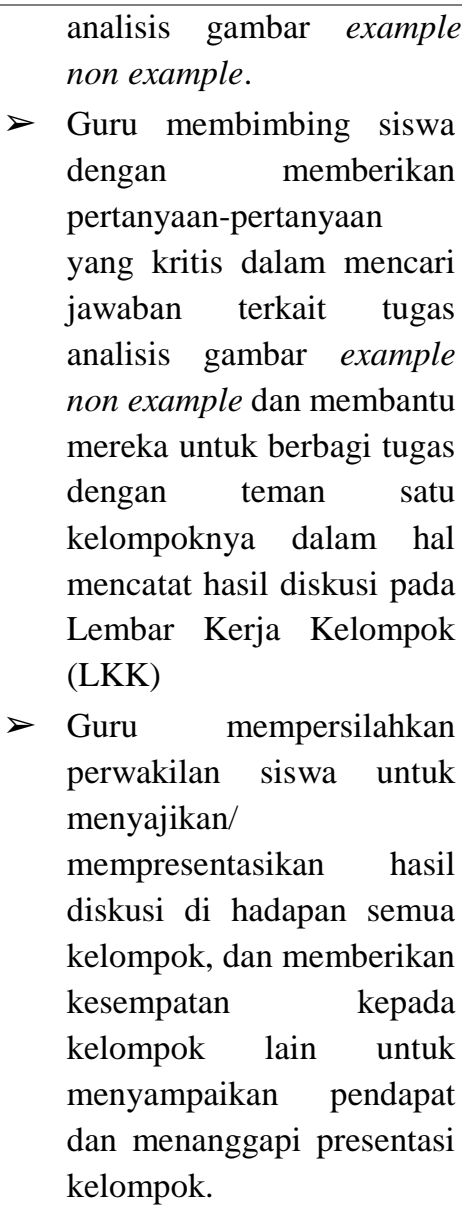 \\
\hline $\begin{array}{l}\text { Fase-5 } \\
\text { Mengevaluas } \\
\text { i pengalaman } \\
\text { belajar }\end{array}$ & $\begin{array}{l}\text { 3erdasarkan hasil diskusi siswa, } \\
\text { guru menyimpulkan materi } \\
\text { sesuai tujuan yang ingin } \\
\text { dicapai. Kemudian guru } \\
\text { mendorong masing-masing } \\
\text { kelompok untuk melakukan } \\
\text { evaluasi pengalaman belajar } \\
\text { tentang proses-proses yang } \\
\text { mereka gunakan selama } \\
\text { melaksanakan diskusi. }\end{array}$ \\
\hline $\begin{array}{l}\text { Fase-6 } \\
\text { Memberikan } \\
\text { penghargaan } \\
\text { kepada } \\
\text { kelompok }\end{array}$ & $\begin{array}{l}\text { Guru memberikan penghargaan } \\
\text { kepada kelompok diskusi } \\
\text { sebagai bentuk apresiasi telah } \\
\text { melaksanakan kegiatan diskusi } \\
\text { belajar dengan baik, dan } \\
\text { membuat siswa lebih semangat } \\
\text { belajar dan menyenangi materi } \\
\text { yang telah dipelajari. }\end{array}$ \\
\hline
\end{tabular}


Selain pemahaman siswa terkait materi himpunan dalam mata pelajaran Matematika, sesuai dengan tujuan kedua penelitian ini yaitu mendeskripsikan keterampilan kooperatif siswa. dalam bukunya Nur, mohamad. dkk. (2000) mengemukakan bahwa ada tiga tingkatan keterampilan kooperatif, yaitu :

1. Keterampilan kooperatif tingkat awal Meliputi: (a) menggunakan kesepakatan; (b) menghargai kontribusi; (c) mengambil giliran dan berbagi tugas; (d) berada dalam kelompok; (e) berada dalam tugas; (f) mendorong partisipasi; (g) mengundang orang lain untuk berbicara; (h) menyelesaikan tugas pada waktunya; (i) menghormati individu.

2. Keterampilan kooperatif tingkat menengah Meliputi: (a) menunjukkan penghargaan dan simpati; mengungkapkan ketidaksetujuan dengan cara yang dapat diterima; (c) mendengarkan dengan aktif; (d) bertanya; (e) membuat ringkasan; (f) menafsirkan; (g) mengatur dan mengorganisir; (h) menerima, tanggung jawab; (i) mengurangi ketegangan.

3. Keterampilan kooperatif tingkat mahir Meliputi: (a) mengolaborasi; (b)

memeriksa dengan cermat; (c)
menanyakan kebenaran;
menetapkan tujuan; dan
berkompromi.

Keterampilan kooperatif siswa yang diamati dalam penelitian ini, hanya dibatasi pada: (a) keterampilan menghargai kontribusi, (b) berada dalam kelompok, (c) mendengarkan, dan (d) bertanya.

\section{METODE PENELITIAN}

Metode penelitian yang digunakan dalam penelitian ini adalah Penelitian Tindakan Kelas (PTK). Menurut Suharsimi Arikunto (2010) penelitian tindakan kelas merupakan kegiatan penelitian yang dilakukan terhadap sejumlah subjek yang menjadi sasaran yaitu peserta didik, bertujuan memperbaiki situasi pembelajaran di kelas agar terjadi peningkatkan kualitas pembelajaran.

Model yang digunakan dalam penelitian ini adalah Model Spiral penelitian tindakannya Bachman (2001) dalam Craig A.Mertler (2014: 19) yang digambarkan pada Gambar 2. sebuah spiral dalam Model penelitian tindakan Bachman terdiri atas : rencana, (b) Tindakan dan Observasi, serta refleksi. 


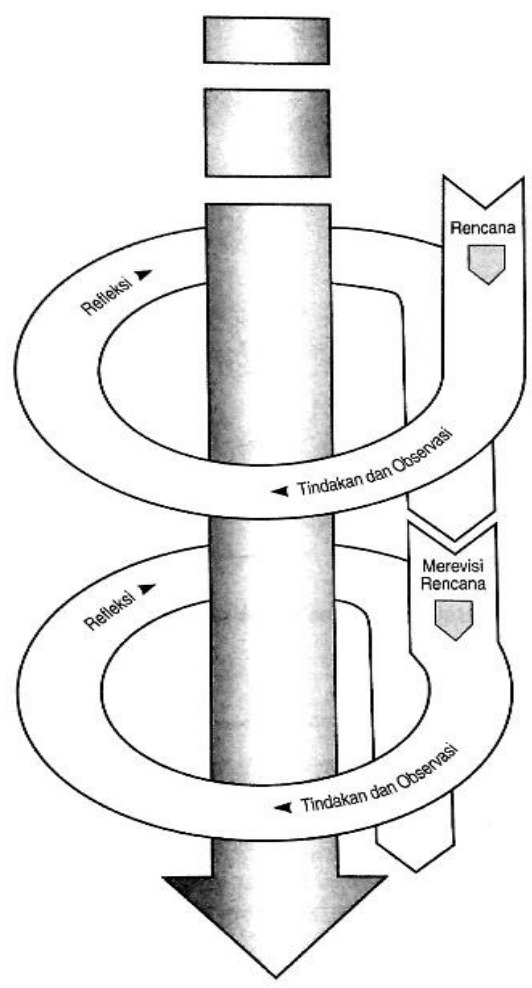

Gambar 2. Model Penelitian Tindakan Bachman

Penelitian Tindakan Kelas ini dilaksanakan di SMPN 2 Socah Bangkalan, dengan subjek penelitian sebanyak 16 siswasiswi kelas VII pada tahun ajaran 20182019.

Teknik pengumpulan data yang digunakan adalah tes dan observasi. Teknik tes dilakukan untuk mengumpulkan data terkait hasil belajar/ pemahaman kognitif siswa. Teknik observasi dilakukan untuk mengumpulkan data terkait keterampilan kooperatif siswa. Instrumen pengumpulan data yang digunakan adalah Tes hasil belajar kognitif dan lembar observasi .

Tes hasil belajar kognitif berisi soalsoal materi himpunan, sedangkan lembar observasi yang disusun berupa tabel yang berisi nama siswa, jenis keterampilan kooperatif, dengan cara pemberikan skor " 1 " jika keterampilan kooperatif ada/ muncul, dan skor "0" jika keterampilan kooperatif tersebut tidak ada/ tidak muncul sama sekali dalam selama pembelajaran.

Analisis data yang digunakan dalam penelitian ini berupa analisis data deskriptif kuantitatif, yang digunakan untuk menganalisis hasil tes belajar siswa (pemahaman) dan hasil observasi. Hasil belajar siswa dianalisis sesuai pedoman penskoran yang telah disiapkan bersamaan dengan soal tes hasil belajar siswa. Sedangkan persentase hasil analisis keterampilan kooperatif siswa diterjemahkan dengan menggunakan interpretasi sebagai berikut.

Tabel 2. Interpretasi keterampilan kooperatif

\begin{tabular}{|l|l|l|}
\hline No. & Persentase $(P)$ & Interpretasi \\
\hline 1 & $80 \%<P \leq 100 \%$ & Sangat Baik \\
\hline 2 & $60 \%<P \leq 80 \%$ & Baik \\
\hline 3 & $40 \%<P \leq 60 \%$ & Cukup \\
\hline 4 & $20 \%<P \leq 40 \%$ & Kurang \\
\hline 5 & $P \leq 20 \%$ & Sangat Kurang \\
\hline
\end{tabular}

\section{HASIL DAN PEMBAHASAN}

\section{Siklus I}

Siklus pertama (siklus I) pada penelitian ini dilaksanakan pada tanggal 1 Agustus 2018. Rencana dalam siklus I 
disajikan dalan Rencana Pembelajaran dengan menggunakan model pembelajaran kooperatif tipe Example Non example yang mengacu pada langkah-langkah pembelajaran pada Tabel 1.

Rata-rata hasil belajar siswa pada siklus I sebesar 68,75. Berdasarkan hasil observasi, pada siklus I diperoleh rata-rata persentase keterampilan kooperatif siswa sebesar 73\%, yang berarti bahwa keterampilan kooperatif siswa tergolong baik. Adapun rincian keterampilan kooperatif pada siklus I disajikan pada Tabel 3 berikut ini.

\section{Tabel 3. Rekapitulasi Keterampilan}

\section{Kooperatif pada Siklus I}

\begin{tabular}{|r|l|c|}
\hline No & Jenis Keterampilan & Total Skor \\
\hline 1 & Menghargai Kontribusi & 12 \\
\hline 2 & Berada dalamkelompok & 15 \\
\hline 3 & Mendengarkan & 14 \\
\hline 4 & Bertanya & 6 \\
\hline \multicolumn{2}{|c|}{ Rata-rata skor total } & 11.75 \\
\hline \multicolumn{2}{c|}{ Skor Maksimal } & 16 \\
\hline \multicolumn{2}{r|}{ Persentase } & $73 \%$ \\
\hline
\end{tabular}

Pada siklus I, terdapat beberapa hal yang perlu direfleksi yaitu : (a) karena siswa pertama kali dalam melakukan pembelajaran dengan model kooperatif tipe example non example, maka alokasi waktu pada fase 1 hingga fase 3 agak lama. Hal dimungkinkan karena siswa membutuhkan waktu dalam penyesuaian terutama dalam hal membiasakan siswa bagaimana belajar secara berkelompok kooperatif (b) siswa masih malu-malu dalam belajar secara berkelompok kooperatif, sehingga masih relative sedikit siswa yang mengemukakan pertanyaan (bertanya) atau mengemukakan pendapat mengacu pada refleksi, hasil pemahaman siswa dan keterampilan kooperatif siswa, maka peneliti menganggap perlu untuk melakukan siklus kedua (siklus II).

\section{Siklus II}

Rencana Pembelajaran pada siklus II masih menggunakan model pembelajaran kooperatif tipe example non example, namun mengacu pada hasil refleksi pada siklus I sebelumnya, maka pembentukkan kelompok telah diumumkan sebelum pembelajaran dimulai. sehingga pada saat pembelajaran dimulai, siswa telah berkumpul bersama kelompoknya masingmasing.

Rata-rata hasil belajar siswa pada siklus I sebesar 82,5. berdasarkan hasil observasi, pada siklus I diperoleh rata-rata persentase keterampilan kooperatif siswa sebesar 91\%, yang berarti bahwa keterampilan kooperatif siswa tergolong sangat baik. Adapun rincian keterampilan kooperatif pada siklus II disajikan pada Tabel 4 berikut ini.

\section{Tabel 4. Rekapitulasi Keterampilan} Kooperatif pada Siklus II 


\begin{tabular}{|c|l|c|}
\hline No & Jenis Keterampilan & Total Skor \\
\hline 1 & Menghargai Kontribusi & 16 \\
\hline 2 & Berada dalamkelompok & 16 \\
\hline 3 & Mendengarkan & 16 \\
\hline 4 & Bertanya & 10 \\
\hline \multicolumn{2}{|c|}{ Rata-rata skor total } & 14.5 \\
\hline \multicolumn{2}{r|}{ Skor Maksimal } & 16 \\
\hline \multicolumn{2}{r|}{ Persentase } & $91 \%$ \\
\hline
\end{tabular}

Mengacu pada hasil belajar kognitif siswa, maka perkembangan pemahaman ssiwa dari siklus I dan siklus 2 dapat disajikan pada Gambar grafik berikut ini.

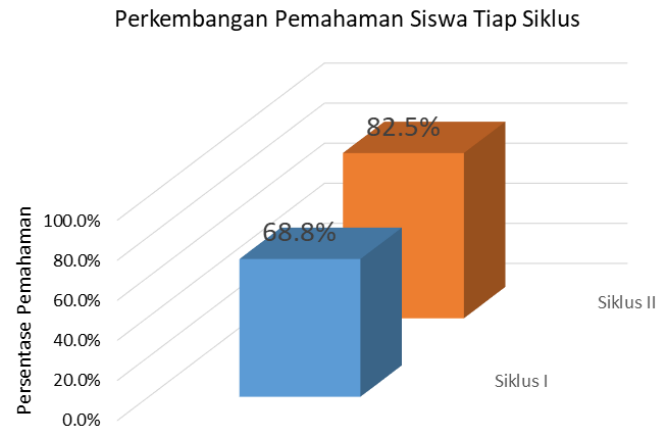

Gambar 3. Grafik Perkembangan

Pemahaman Siswa Tiap Siklus

Sedangkan, perkembangan keterampilan kooperatif siswa secara klasikal, disajikan pada Gambar grafik berikut ini.

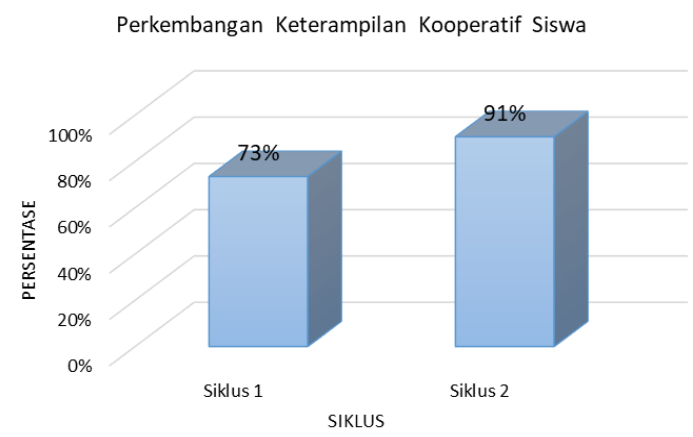

Gambar 4. Grafik Perkembangan

Keterampilan Kooperatif Siswa Tiap

Siklus

\section{PENUTUP Simpulan}

Beberapa hal yang dapat disimpulkan dari penelitian tindakan kelas ini antara lain:

1. Model pembelajaran kooperatif tipe example non example dapat digunakan sebagai salah satu alternative dalam meningkatkan pemahaman siswa dalam mempelajari materi himpunan, hal ini ditunjukkan dengan adanya peningkatan persentase pemahaman siswa dari $68,8 \%$ (siklus I) menjadi $82,5 \%$ (siklus II).

2. Model pembelajaran kooperatif tipe example non example dapat digunakan sebagai salah satu alternatif dalam meningkatkan keterampilan kooperatif siswa dalam pembelajaran materi himpunan, hal ini ditunjukkan dengan adanya peningkatan persentase pemahaman siswa dari $73 \%$ (siklus I) menjadi 91\% (siklus II). Dalam hal ini, keterampilan kooperatif siswa yang diamati dalam pembelajaran antara lain : (a) keterampilan menghargai kontribusi, (b) berada dalam kelompok, (c) mendengarkan, dan (d) bertanya. 


\section{Saran}

Adapun beberapa saran yang dapat disumbangkan, sebagai hasil refleksi selama penelitian ini dilaksanakan antara lain:

1. Bagi guru

a) Bilamana akan menerapkan model pembelajaran kooperatif, diharapkan dapat memperhatikan pengelolaan waktu, agar kegiatan pembelajaran dengan menggunakan model pembelajaran kooperatif tipe example non example berlangsung baik, terutama pada saat pengorganisasian kelompok yang memerlukan waktu.

b) Guru/ pendidik diharapkan banyak menggunakan model pembelajaran yang banyak mengaktifkan siswa, sebagai upaya untuk meningkatkan keterampilan kooperatif siswa.

2. Bagi peneliti

Diharapkan dapat menambah komponen keterampilan kooperatif yang lebih banyak, dalam rangka upaya untuk mengembangkan keterampilan pada penelitian berikutnya.

\section{DAFTAR PUSTAKA}

Arikunto, Suharsimi. 2010. Prosedur Penelitian: Suatu Pendekatan Praktik. Jakarta: Rineka Cipta.

Akbar, Sa'dun. 2013. Instrumen Perangkat Pembelajaran. Bandung: Remaja Rosdakarya.

Huda, Miftahul. 2012. Cooperative Learning: Metode, teknik, struktur dan model terapan. Yogyakarta: Pustaka Belajar.

Ibrahim, Muslimin, dkk. 2000. Pembelajaran Kooperatif. Surabaya: University Press.

Kurniasih, Imas. dan Berlin, S. 2017. Ragam Pengembangan Model Pembelajaran: Untuk Peningkatan Profesionalitas Guru. Jakarta: Kata Pena.

Mertler, Craig A. 2014. Penelitian Tindakan Kelas : Meningkatkan Sekolah dan Memberdayakan Pendidik. Jakarta: Indeks.

Nur, mohamad., Muchlas Samani, dkk. 2000. Keterampilan Kooperatif (buku ajar mahasiswa). Universitas Negeri Surabaya. 
Rusman. 2014. Model-model Pembelajaran: Mengembangkan Profesionalisme Guru. Jakarta: Rajawali Press

Siberman, Melvin L. 2014. Active Learning: 101 Cara Belajar Siswa Aktif. Bandung: Nuansa Cendekia.

Shoimin, Aris. 2014. 68 Model Pembelajaran Inovatif dalam Kurikulum 2013. Yogyakarta: Ar-Ruzz Media

Sugiyono . (2016). Metode Penelitian \& Pengembangan. Bandung: Alfabeta

Sugiyono. (2014). Metode Penelitian kuantitatif, kualitatif dan R \& B. Bandung: Alfabeta

Yuliantoro, Agus. 2015. Penelitian Tindakan Kelas dengan Metode Mutakhir. Yogyakarta: ANDI OFFSET. 